\title{
Corepressive function of nuclear receptor coactivator 2 in androgen receptor of prostate cancer cells treated with antiandrogen
}

Keisuke Takeda ${ }^{1}$, Noboru Hara ${ }^{1,2,3^{*}}$, Tsutomu Nishiyama ${ }^{1}$, Masayuki Tasaki ${ }^{1}$, Fumio Ishizaki ${ }^{1}$ and Yoshihiko Tomita $^{1}$

\begin{abstract}
Background: Recruitment of cofactors in the interaction of the androgen receptor (AR) and AR ligands plays a critical role in determining androgenic/antiandrogenic effects of the AR ligand on signaling, but the functions of key cofactors, including nuclear receptor coactivator (NCOA), remain poorly understood in prostate cancer cells treated with AR ligands.

Methods: We examined prostate cancer cell lines LNCaP and VCaP expressing mutated and wild-type ARs, respectively, to clarify the significance of NCOAs in the effect of antiandrogens. Hydroxyflutamide showed antagonistic activity against VCaP and an agonistic effect on LNCaP. Bicalutamide served as an antagonist for both. We analyzed mRNA transcription and protein expression of NCOAs in these cells pretreated with dihydrotestosterone and thereafter treated with the mentioned antiandrogens. Transcriptional silencing of candidate NCOAs and AR was performed using small interfering RNA (siRNA). Cell proliferation was evaluated with MTT assay.

Results: LNCaP treated with bicalutamide showed an about four-fold increase in the expression of NCOA2 mRNA compared to those pretreated with dihydrotestosterone alone $(P<0.01)$. In VCaP pretreated with dihydrotestosterone, transcriptions of NCOA2 and NCOA7 were slightly increased with bicalutamide (1.96- and 2. 42-fold, respectively) and hydroxyflutamide (1.33-fold in both). With Western blotting, the expression of NCOA2 protein also increased in LNCaP cells treated with bicalutamide compared with that in control cells pretreated with dihydrotestosterone alone. Following silencing with siRNA for NCOA2, PSA levels in media with LNCaP receiving bicalutamide were elevated compared with those in non-silencing controls $(101.6 \pm 4.2 \mathrm{vs.} 87.8 \pm 1.4 \mathrm{ng} / \mathrm{mL}$, respectively, $P=0.0495)$. In $L N C a P$ cells treated with dihydrotestosterone and bicalutamide, NCOA2-silencing was associated with a higher proliferation activity compared with non-silencing control and AR-silencing.
\end{abstract}

Conclusion: NCOA2, which has been thought to be recruited as a coactivator, possibly plays a corepressive role in AR of prostate cancer cells when treated with antiandrogens, suggesting its potential as a therapeutic target.

Keywords: Androgen receptor, Antiandrogen, Coactivator, Corepressor

\footnotetext{
* Correspondence: harasho@med.niigata-u.ac.jp; noboharasho@par.odn.ne.jp 'Division of Urology, Department of Regenerative and Transplant Medicine, Graduate School of Medical and Dental Sciences, Niigata University, Niigata, Japan

${ }^{2}$ Division of Molecular Oncology, Department of Signal Transduction Research, Graduate School of Medical and Dental Sciences, Niigata University, Niigata, Japan

Full list of author information is available at the end of the article
} International License (http://creativecommons.org/licenses/by/4.0/), which permits unrestricted use, distribution, and reproduction in any medium, provided you give appropriate credit to the original author(s) and the source, provide a link to the Creative Commons license, and indicate if changes were made. The Creative Commons Public Domain Dedication waiver (http://creativecommons.org/publicdomain/zero/1.0/) applies to the data made available in this article, unless otherwise stated. 


\section{Background}

NR3C4 (nuclear receptor subfamily 3, group C, member 4), also well-known as the androgen receptor (AR), is a member of the nuclear hormone receptor superfamily of ligandregulated transcription factors [1, 2]. It has been wellestablished that the androgen-AR interaction is involved in the proliferation of both benign and malignant prostate epithelial cells, and the role played by the androgen-AR interaction has been a therapeutic target [3, 4]. Androgen deprivation therapy (ADT) has thus been the mainstay for patients with metastatic prostate cancer and non-metastatic high-risk disease to prevent recurrence after definitive local therapy $[5,6]$.

Patients who have undergone ADT often show resistance to it, and develop castration-resistant prostate cancer (CRPC) [2, 7]. Despite being refractory to ADT, experimental studies as well as clinical practice suggest that CRPC has AR, which remains transcriptionally and functionally active beyond late-stage disease; human kallikrein (KLK) 3/prostate-specific antigen (PSA), whose production is regulated by androgen-dependent transcription, continues to elevate in the serum in men with CRPC receiving ADT $[2-4,8]$. Such contradictions cannot be explained just by AR mutations or amplification [9]. Recently, the agonistic or antagonistic role of the AR ligand has been shown to be determined by the recruitment profile of cofactors in the AR complex, and it has also been suggested that the altered recruitment of cofactors in the androgen-AR interaction and the signaling pathway thereof are involved in the development of CRPC, and possibly have an impact on oncological outcomes [10-12]; however, relevant studies are limited.

Combined castration and peroral antiandrogens/AR-antagonists have been associated with better survival outcomes in men with prostate cancer compared with castration alone, although some studies suggest that their advantage may be limited in advanced disease $[4,5,7]$. Interestingly, antiandrogens represented by bicalutamide and hydroxyflutamide can give an agonistic effect; castrated men treated with antiandrogens, who have disease progression thereafter, occasionally show an decrease in serum PSA and improvement in disease following the discontinuation of them. This phenomenon of disease remission after the withdrawal of antiandrogens has been regarded as antiandrogen-withdrawal syndrome, and men showing such PSA reduction are associated with better oncological outcomes [13-15]. Correspondingly, a few exploratory studies reported that commonly used antiandrogens showed agonistic activity in cells with increased AR levels [16]; the altered arrangement or recruitment of coactivators and corepressors to the promoters of AR target genes may account for the mentioned antagonistagonist conversion. Additionally, enhanced expressions of AR possibly intensify signaling from low levels of residual ligands, and change the normal response to antiandrogens, leading to resistance to them. However, roles played by cofactors in AR complex in prostate cancer cells remain unclear; approaching them may clarify the mechanism of castration resistance as well as antiandrogen withdrawal syndrome, potentially developing innovative therapy.

In the present study, we examined the expression profile of AR cofactors in prostate cancer cells under various hormonal conditions in the presence/absence of antiandrogens to clarify the significance of nuclear receptor coactivators (NCOAs) in the effect of antiandrogens, and to identify cofactors as targets for prostate cancer treatment.

\section{Methods}

Cells, agents, and antibodies

The protocol of this research project was approved by a suitably constituted Ethics Committee of Niigata University School of Medicine (\#2050), and all experimental protocols for cell experimentation did not require ethical review and approval. Human prostate cancer cell lines $\mathrm{LNCaP}$ and $\mathrm{VCaP}$ were purchased from the American Type Culture Collection (Manassas, VA, USA). Hydroxyflutamide and bicalutamide, antagonists against AR, were purchased from Toronto Research Chemicals Inc. (Toronto, Canada) and Tocris Bioscience (Bristol, UK), respectively. Testosterone and dihydrotestosterone (DHT) were purchased from Steraloids (Wilton, NH, USA). Anti-NCOA2 (ab10491, Lot: GR167494-1) was obtained from Abcam plc. (CAMRIDGE, UK). Anti-beta actin (A5441, Lot: 122M478V) was obtained from SIGMA-ALDRICH Corp. (St. Louis, MO, USA).

\section{Cell culture}

Cells were cultured in Roswell Park Memorial Institute1640 (Gibco; Life Technologies, Carlsbad, CA, USA), supplemented with $10 \%$ heat-inactivated fetal bovine serum (FBS), 1 \% MEM nonessential amino acids, $1 \%$ sodium pyruvate solution $100 \mathrm{mM}, 0.14 \% \mathrm{NaHCO}_{3}$, and $80 \mathrm{mg} / \mathrm{L}$ of kanamycin, at $37{ }^{\circ} \mathrm{C}$ in a humidified, $5 \%$ $\mathrm{CO}_{2}$ atmosphere. These cells grown to subconfluence were switched to steroid hormone-depleted medium without phenol-red, containing $10 \%$ charcoal-dextran stripped FBS (Biowest, Paris, France), and were then exposed to hydroxyflutamide or bicalutamide at $10^{-5} \mathrm{M}$ for 3 days. For the Tandem-R PSA test (Beckman Coulter Inc., San Diego, CA, USA) in media, cells were plated at a population of $1 \times 10^{5}$ cells $/ \mathrm{mL}$ in triplicate.

\section{RNA extraction and quantification of gene expression by quantitative-PCR}

We analyzed mRNA transcription levels of cofactors in LNCaP and VCaP cells pretreated with DHT of $10^{-9} \mathrm{M}$ 
and thereafter treated with bicalutamide or hydroxyflutamide at $10^{-5} \mathrm{M}$. mRNA expressions of AR-related genes were determined by quantitative PCR. Cells were plated at a concentration of $5 \times 10^{5}$ cells per $25-\mathrm{cm}^{2}$ flasks (5 mL of media) (Falcon Labware, Lincoln Park, NJ, USA) for RNA isolation. Total RNA was isolated with Ambion's RNAqueous-4PCR Kit (Applied Biosystems; Life Technologies) and cDNA was synthesized by reverse-transcription according to the protocol of the High-Capacity cDNA Reverse Transcription Kits (Applied Biosystems). The expression levels of genes and the internal reference beta-actin were estimated using quantitative PCR with the TaqMan system and ABI 7500 Sequence Detection System (Applied Biosystems). The detectors/probes were purchased from Applied Biosystems. Each experiment was triplicated, and we used the deltadelta $\mathrm{Ct}$ method for analysis. An increase with ratio values of 2.5-fold or higher in the transcription was considered indicative of significant overexpression $[17,18]$.

\section{Transcriptional silencing using small interfering RNA (siRNA)}

LNCaP cells (passage number: 19 times) cultured in steroid hormone-depleted media containing $10 \%$ charcoaldextran stripped FBS were treated with $10^{-9} \mathrm{M}$ DHT, and were prepared for the transfection of si-RNAs. A total of $5 \times 10^{5} \mathrm{LNCaP}$ cells were resuspended in $100 \mu \mathrm{L}$ of buffer $\mathrm{R}$ with $5 \times 10^{-6} \mathrm{M}$ siRNA for NCOA2 or control non-silencing siRNA, and were transfected in $100 \mu \mathrm{L}$ of Neon tip with the Neon transfection system (Life Technologies) using two pulses $(1,100-\mathrm{V}$ input pulse voltage/20-ms input pulse width). NCOA2-transfected cells were plated at a concentration of $1 \times 10^{5}$ cells/ $\mathrm{mL}$ per $25-\mathrm{cm}^{2}$ flasks, and cultured in phenol-red free media with $10 \%$ charcoal-dextran stripped of FBS with DHT of $10^{-9}$ for 3 days before the experiment. Functions of cofactors with small interfering RNA (siRNA)-based silencing were evaluated by measuring the concentration of PSA in cell culture media [19].

\section{Protein extract and Western blot assays}

The cell tissues were prepared in lysis solution (PBS containing $1.0 \%$ Triton-X 100 and 20 mM HEPES), and the supernatant was collected after being centrifuged at $25,000 \times \mathrm{g}$ for $30 \mathrm{~min}$ at $4{ }^{\circ} \mathrm{C}$. Aliquots of proteins $(24 \mu \mathrm{g}$ of each sample) were prepared using sample buffer, heated for denaturing at $70{ }^{\circ} \mathrm{C}$ for $10 \mathrm{~min}$, and separated on a $10 \%$ Bis-Tris SDS-PAGE gel. Subsequently, they underwent electrophoresis and were transferred to PVDF membranes using iBlot Gel Transfer Stacks and the iBlot Dry Blotting System (Novex; Life Technologies). Membranes were preincubated for one $\mathrm{hr}$ at room temperature with blocking buffer (5\% skim milk and $0.1 \%$ Tween20 in $\mathrm{PBS}$ ), and incubated with the first antibody (NCOA2 [ab10491], 1:500 dilution) overnight at $4{ }^{\circ} \mathrm{C}$. Thereafter, membranes were exposed to peroxidase-labeled second antibodies for $1 \mathrm{~h}$ at room temperature. Protein expressions were visualized using the ECL Prime System (GE Healthcare, Buckinghamshire, UK) and a cooled CCD camera system (AE-9300z, ATTO CORP, Tokyo, Japan).

\section{MTT assay}

A total of $5 \times 10^{5} \mathrm{LNCaP}$ cells were resuspended in $10 \mu \mathrm{L}$ of buffer $\mathrm{R}$ with $5 \times 10^{-6} \mathrm{M}$ siRNA for NCOA2, $\mathrm{AR}$, or non-silencing control, and were transfected in $10 \mu \mathrm{L}$ of Neon tip with the Neon transfection system (Life Technologies) using two pulses $(1,100-\mathrm{V}$ input pulse voltage/20-ms input pulse width). Cells were plated at a concentration of $5 \times 10^{5}$ cells $/ \mathrm{mL}$ per 96 -well assay plate, and were cultured in phenol-red free media with $10 \%$ charcoal-dextran stripped of FBS with DHT of $10^{-9}$. Twenty $\mu$ l of Celltiter 96 AQueous One Solution Reagent (Promega, Fitchburg, WI, USA) were pipetted into wells containing $100 \mu \mathrm{l}$ of culture medium, incubated the plate at $37{ }^{\circ} \mathrm{C}$ in a humidified, $5 \% \mathrm{CO}_{2}$ atmosphere, and subsequently, the absorbance at $490 \mathrm{~nm}$ was recorded using iMARK (BIO-RAD, Hercules, CA, USA). Assays were performed every $24 \mathrm{~h}$ for 3 days.

\section{Statistical analysis}

The Kruskal-Wallis test was used to verify the significance in differences in expression level of mRNA and cell proliferation analysis with MTT assay. The MannWhitney $U$ test was used to compare changes in paired parameters before and after siRNA. The test was twosided and $p<0.05$ was considered significant. All analyses were performed using SPSS version 15.0 J (SPSS Inc., Chicago, IL, USA) on a Windows-based computer.

\section{Results}

Effects of bicalutamide or hydroxyflutamide treatment on KLK3/PSA and AR transcription in prostate cancer cells pretreated with DHT

In $\mathrm{VCaP}$ cells cultured in DHT-added media, the transcription level of KLK3/PSA with quantitative PCR was markedly reduced with bicalutamide treatment (0.05fold, Fig. 1); this was also the case with hydroxyflutamide treatment (0.04-fold, Fig. 2). In LNCaP cells pretreated with DHT, KLK3/PSA transcription was downregulated with bicalutamide treatment (0.28-fold, Fig. 3), while hydroxyflutamide treatment clearly increased the transcription level of KLK3/PSA (2.90-fold, Fig. 4).

In $\mathrm{VCaP}$ cells cultured in DHT-added media, bicalutamide and hydroxyflutamide treatment significantly upregulated the transcription of $\mathrm{AR}$ (3.39- and 2.51-fold, respectively) (Figs. 1 and 2). In LNCaP cells pretreated with DHT, bicalutamide treatment slightly increased AR transcription (1.24-fold, Fig. 3), whereas AR 


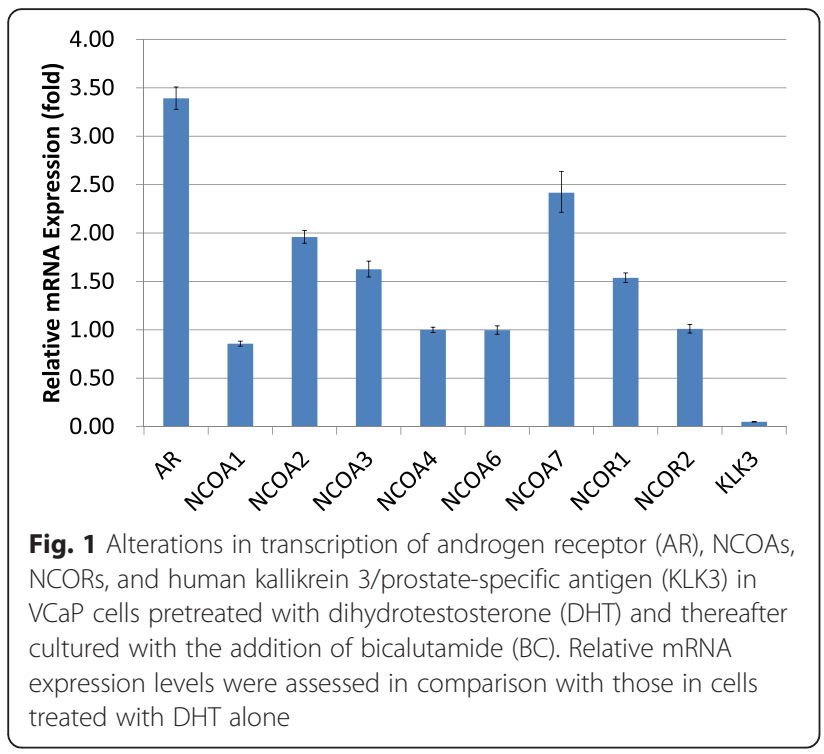

transcription decreased with hydroxyflutamide (0.44fold, Fig. 4).

\section{Impact of bicalutamide or hydroxyflutamide treatment on the transcription of NCOA and nuclear receptor corepressor (NCOR) families}

Transcriptions of NCOA2 and NCOA7 were also elevated with bicalutamide (1.96- and 2.42-fold, respectively, Fig. 1) and hydroxyflutamide (1.33-fold in both, Fig. 2) in VCaP cells pretreated with DHT. LNCaP cells pretreated with DHT receiving bicalutamide showed a 4-fold increase in the expression of NCOA2 mRNA compared with those cultured with DHT pretreatment alone (Fig. 3); transcription levels of other coactivators such as NCOA1, NCOA3, and NCOA4 did not increase with bicalutamide. Also, corepressors such as NCOR1

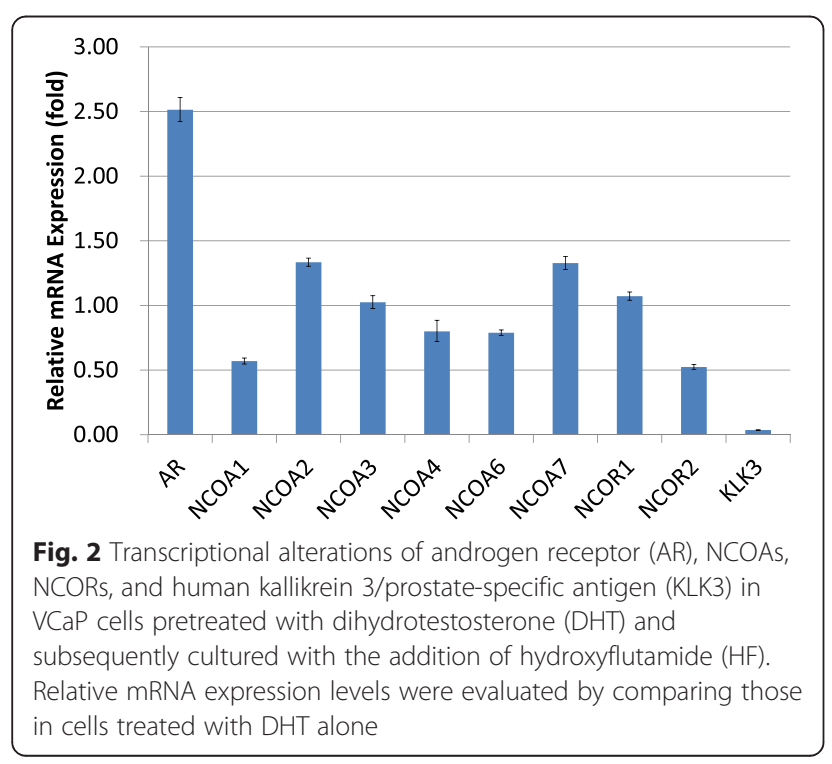

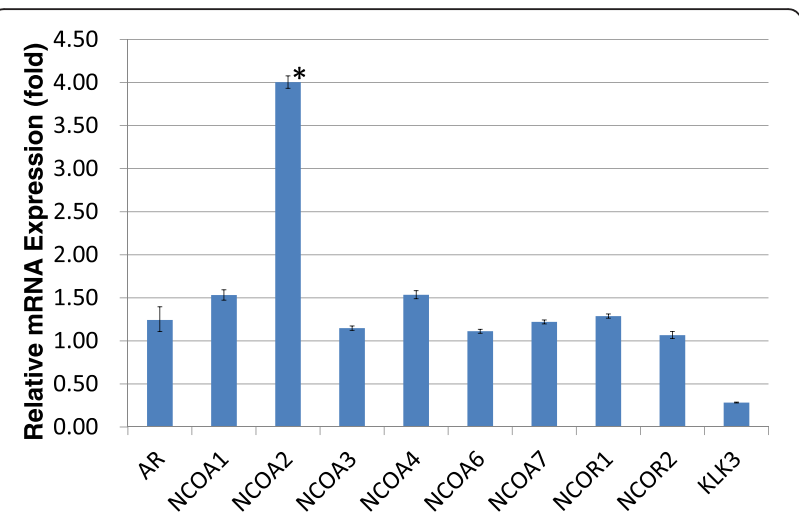

Fig. 3 Alterations in transcription of androgen receptor (AR), NCOAs, NCORs, and human kallikrein 3/prostate-specific antigen (KLK3) in LNCaP cells pretreated with dihydrotestosterone (DHT) and thereafter cultured with the addition of bicalutamide (BC). Relative mRNA expression levels were assessed in comparison with those in cells treated with DHT alone. ${ }^{*} P<0.01$ (Kruskal-Wallis test)

and NCOR2 did not show an increase in the transcription level.

\section{Influence of knock-down of NCOA2 in LNCaP cells on the production of KLK3/PSA}

We also established knock-down models of NCOA2 in $\mathrm{LNCaP}$ cells with transcriptional silencing using small interfering RNA (siRNA). Transcription levels of NCOA2 were significantly reduced compared with negative controls (Fig. 5). Thereafter, knock-down of NCOA2 with siRNA showing most efficient silencing was performed in LNCaP cells pretreated with DHT; the KLK3/PSA concentration in media increased compared with that in non-silencing controls (Fig. 6, $P=0.0495)$.

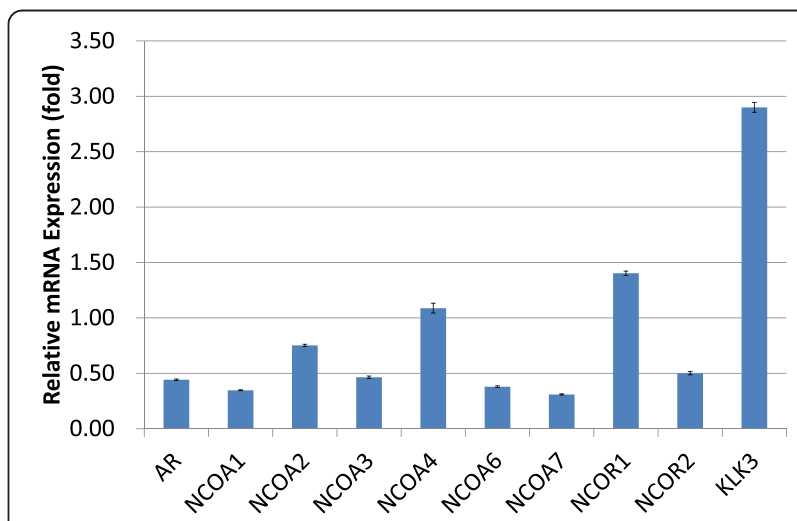

Fig. 4 Transcriptional alterations of androgen receptor (AR), NCOAs, NCORs, and human kallikrein 3/prostate-specific antigen (KLK3) in $\mathrm{LNCaP}$ cells pretreated with dihydrotestosterone (DHT) and subsequently cultured with the addition of hydroxyflutamide (HF). Relative mRNA expression levels were evaluated in comparison with those in cells treated with DHT alone 


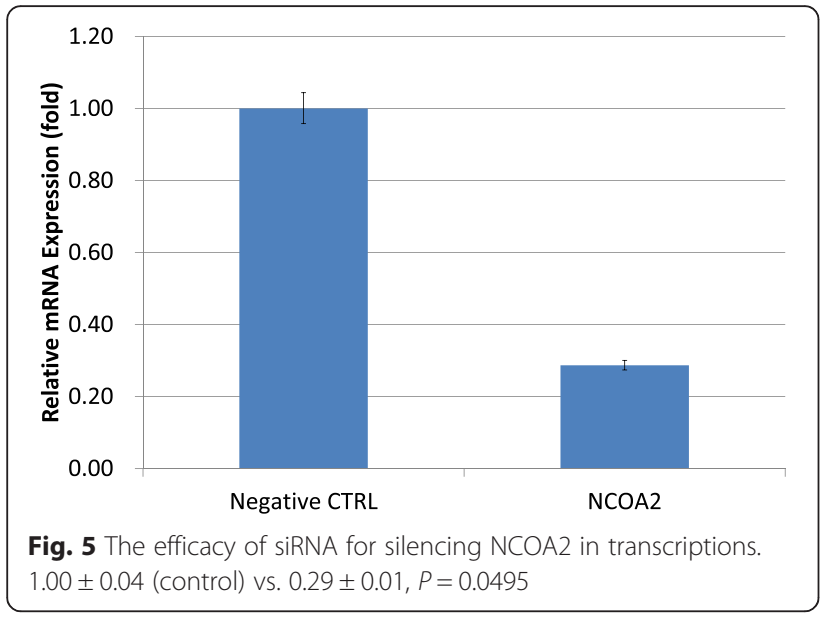

Protein expressions of NCOA2 in LNCaP cells cultured with DHT and bicalutamide

With Western blotting, LNCaP cells pretreated with DHT showed an increased protein level of NCOA2 with bicalutamide than those without (Fig. 7).

\section{Alterations in cell proliferation of LNCaP with silencing of NCOA2 or AR}

There was no difference among proliferations in the NCOA2-silencing, AR-silencing, and non-silencing cells cultured with dihydrotestosterone alone (Fig. 8). Relative absorbance with MTT assay in LNCaP cells cultured with DHT plus bicalutamide was shown in Fig. 9. Cells with NCOA2-silencing showed a higher proliferation activity compared with non-silencing control cells and those with AR-silencing.

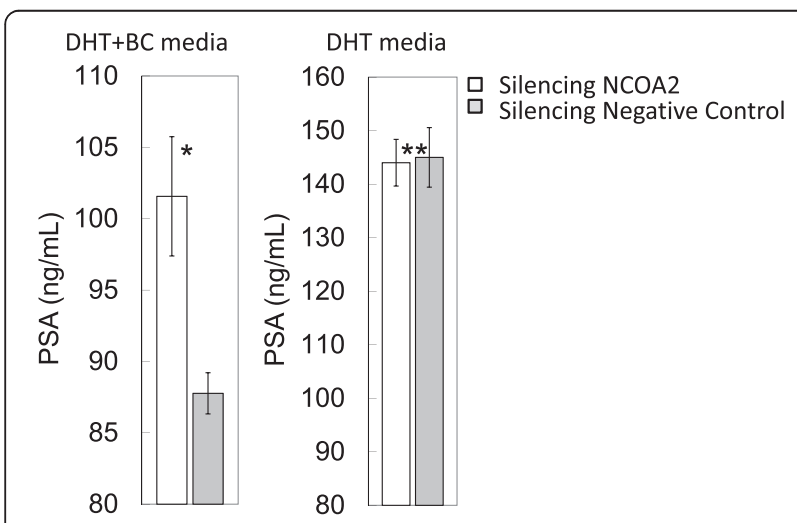

Fig. 6 Impact of knock-down of NCOA2 using siRNA on the production of prostate-specific antigen (PSA) in LNCaP cells cultured with dihydrotestosterone (DHT) plus bicalutamide (BC) (left columns) and those treated with DHT alone. ${ }^{*} 101.6 \pm 4.2 \mathrm{vs} .87 .8 \pm 1.4 \mathrm{ng} / \mathrm{mL}$, respectively, $P=0.0495,{ }^{* *} 144 \pm 4.4$ vs. $145 \pm 5.6 \mathrm{ng} / \mathrm{mL}$, respectively, n.s

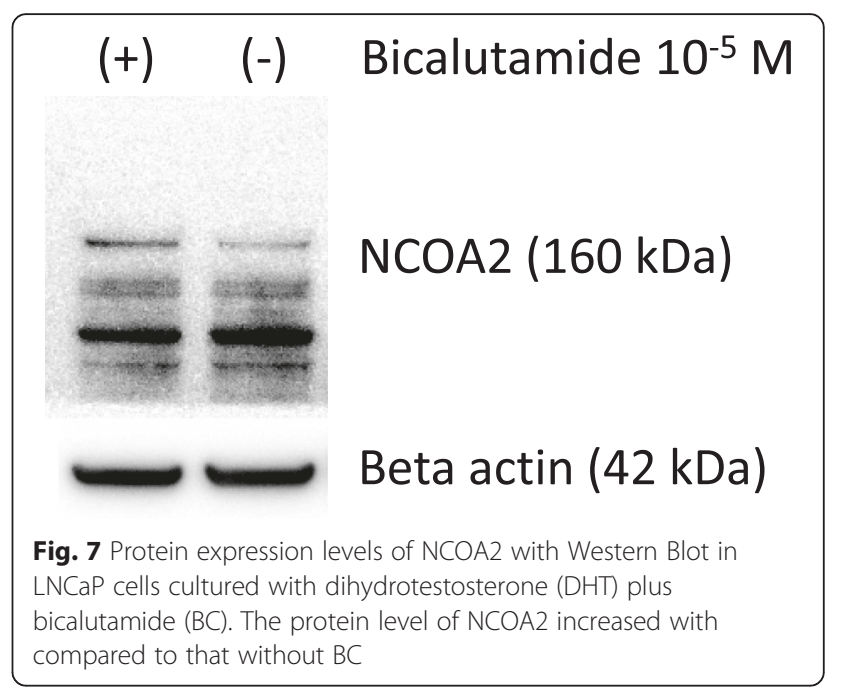

\section{Discussion}

LNCaP and VCaP cells have mutated and wild-type AR, respectively [20, 21]. Hydroxyflutamide has an agonistic effect on LNCaP cells, and bicalutamide serves as an antagonist against them [22, 23]. For VCaP cells, the effect of these antiandrogens has not been determined. In the current study, both bicalutamide and hydroxyflutamide treatments reduced KLK3/PSA transcription in $\mathrm{VCaP}$ cells (Figs. 1 and 2), while the former decreased and the latter increased KLK3/PSA transcription in LNCaP (Figs. 3 and 4), suggesting the different nature of AR in the response to antiandrogens between the two cell types. The transcriptional regulation in AR in response to antiandrogens also differed between $\mathrm{VCaP}$ and LNCaP cells (Figs. 1, 2, 3 and 4), but bicalutamide inhibited KLK3/PSA transcription in both $\mathrm{VCaP}$ and $\mathrm{LNCaP}$ cells to a similar extent.

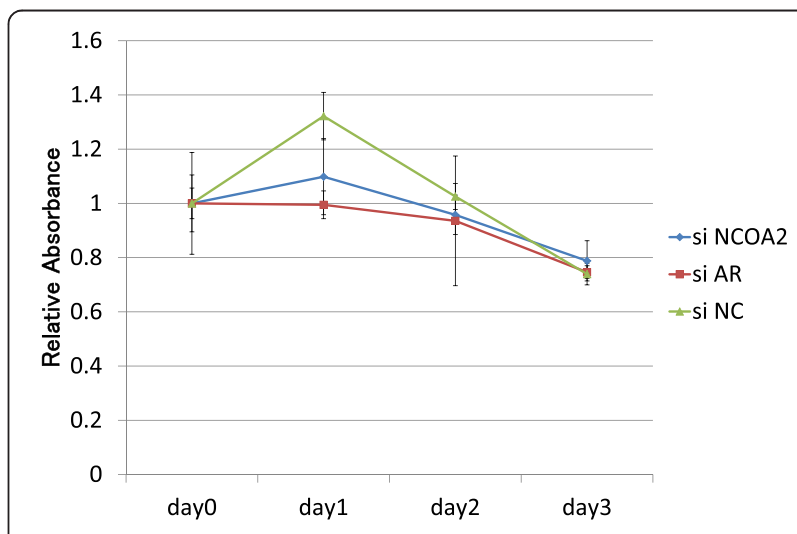

Fig. 8 Relative absorbance with MTT assay in LNCaP cells cultured with dihydrotestosterone. There was no difference among proliferations in the NCOA2-silencing, AR-silencing, and non-silencing cells 


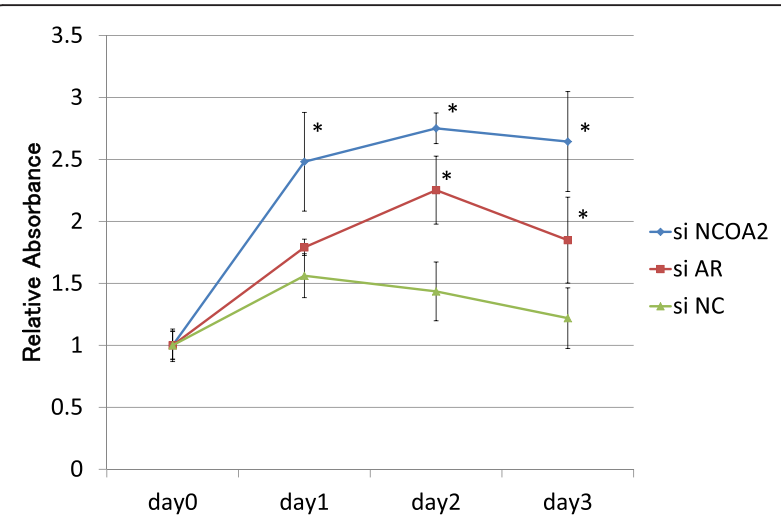

Fig. 9 Relative absorbance with MTT assay in LNCaP cells cultured with dihydrotestosterone (DHT) plus bicalutamide (BC). NCOA2silencing cells showed an increased proliferation compared with nonsilencing control cells and those with silencing androgen receptor (AR). LNCaP cells with silencing AR showed decreased proliferation compared with those silencing NCOA2. ${ }^{*} P<0.01$ (Kruskal-Wallis test)

The present study verified that the absence of DHT negated the role of antiandrogens; transcriptions of AR, NCOAs, and KLK3/PSA were not altered by antiandrogens in the androgen-deprived milieu, except for KLK3/ PSA being increased by hydroxyflutamide. In the absence of endogenous ligands, AR is segregated in the cytoplasm, with its nuclear localization sequence (NLS) masked by heat-shock proteins. Binding to ligands and the separation of these chaperones cause AR to dimerize, and lead to conformational changes and the exposure of the NLS [24-27]. Thus, the nuclear translocation of AR and binding to androgen response elements (AREs) activate androgen-responsive genes. This process is transcriptionally regulated and posttranscriptionally modified through various mechanisms involving interactions with multiple coactivator and corepressor proteins [28-30]. AR activity is modulated by the recruitment of multitudes of positive and negative cofactors, being closely associated with the regulation of protein stability, interaction with others, intracellular receptor localization, and alteration of the AR structure. Thus, the elucidation of cofactor-related modifications of AR may be a promising approach to develop novel and efficient therapeutic options.

In our study, the transcription level of NCOA2 increased with bicalutamide treatment in LNCaP cells (Figs. 3 and 7); transcription levels of other coactivators were not altered. On the other hand, such upregulation of NCOA2 was not marked in $\mathrm{VCaP}$, and the difference may possibly be due to the aforementioned issues in AR and the response to antiandrogens being different between the 2 types of cell. Moreover, knock-down of NCOA2 in LNCaP cells increased the KLK3/PSA concentration in media (Figs. 5 and 6), and cell proliferation analysis with MTT assay further supported the mentioned novel finding (Figs. 8 and 9); NCOA2 is possibly associated with the downregulation of AR signaling in prostate cancer cells treated with bicalutamide. In the presence of bicalutamide, interestingly, knock-down of NCOA2 was associated with a higher cell proliferation than knockdown of AR. These results suggest that NCOA2 plays an inhibitory role in prostate cancer cells treated with bicalutamide. Steroid receptor coactivators represented by NCOA2 and NCOA3 are key regulators, having multiple effects, of transcription factors necessary for cancer cell proliferation, survival, and metastasis [31]. Their overexpression and/or overactivation has been shown in a number of human cancers with various genomic, transcriptional, and posttranslational mechanisms, and are associated with refractory disease leading to poor outcomes [31]. In human prostate cancer, NCOAs have been reported to regulate cell proliferation and invasion and be involved in castration resistance, coupled with AR transcriptional activity [32-34]. NCOA2 has therefore been shown to play a role as a coactivator in the androgen-AR interaction [35-38]; however, there has been no study examining the function of NCOAs in prostate cancer cells treated with antiandrogens. The current results suggest that NCOA2 may possibly explain the reduction of PSA on the withdrawal or conversion of antiandrogens; it possibly also serves as a corepressor in the presence of antiandrogens in prostate cancer cells pretreated with androgens. It is thus necessary to characterize the functional and recruitment profile of each cofactor-AR complex and signaling in prostate cancer in accordance with antagonists as well as agonists.

The present study had several limitations. With the current cell lines and hormonal milieu, cell proliferation assays lack in reproducibility. Knock-down studies with siRNA require further verification of the response, and the application of different siRNAs is necessary to rule out unrelated effects.

\section{Conclusions}

Although the recruitment of NCOA2 has been thought to induce agonistic signaling in $A R$, the current study showed that it possibly also serves as a corepressor in the presence of antiandrogens in prostate cancer cells cultured in a physiological hormonal milieu, suggesting its potential as a therapeutic target for prostate cancer. Characterization of the function and recruitment profile of each cofactor related to AR signaling brought about by various AR ligands may lead to advanced therapy for men with prostate cancer.

\section{Additional files}

Additional file 1: Figure S1. Screening of the siRNA efficacy on target mRNA expression levels. Catalog numbers were s20580, s20581, and s20582 (Neon Transfection System; Life Technologies, Carlsbad, CA, USA) 
for siRNA NCOA2 \#1 (siNCOA2 \#1), \#2 (siNCOA2 \#2), and \#3 (siNCOA2 \#3), respectively. Based on this result, siRNA NCOA2 \#2 was selected, and the relevant data were indicated in Fig. 5. (DOC $54 \mathrm{~kb}$ )

Additional file 2: Table S1. Ct values of gene expression assessed by quantitative PCR in VCaP cells cultured with dihydrotestosterone-added media. Delta-delta Ct value was calculated from the following formula: delta(target gene $\mathrm{Ct}$ - internal control $\mathrm{Ct}$ ) with specific cell culture media - delta(target gene Ct - internal control Ct) with standard cell culture media. (DOC $32 \mathrm{~kb}$ )

Additional file 3: Table S2. Ct values of quantitative PCR in VCaP cells cultured with dihydrotestosterone- and bicalutamide-added media. (DOC $31 \mathrm{~kb})$

Additional file 4: Table S3. Ct values of quantitative PCR in VCaP cells cultured with dihydrotestosterone- and hydroxyflutamide-added media. (DOC $31 \mathrm{~kb}$ )

Additional file 5: Table S4. Ct values of quantitative PCR in $L N C a P$ cells cultured with dihydrotestosterone-added media. (DOC $31 \mathrm{~kb}$ )

Additional file 6: Table S5. Ct values of quantitative PCR in $L N C a P$ cells cultured with dihydrotestosterone- and bicalutamide-added media. (DOC $31 \mathrm{~kb})$

Additional file 7: Table S6. Ct values of quantitative PCR in $L N C a P$ cells cultured with dihydrotestosterone- and hydroxyflutamide-added media. (DOC $31 \mathrm{~kb}$ )

Additional file 8: Figure S2. Full membranes of Western blotting (corresponding to Fig. 7). The membrane in the left panel showed NCOA2 staining part, and the right showed actin beta staining part Starting from the left lane, NCOA2 expressions in LNCaP with bicalutamide and without bicalutamide, and positive control were shown. Twenty-seven ug of Jurkat cell lysate (Catalog \#611451, BD Biosciences, Franklin Lakes, NJ, USA) was used as positive control. Densitometry data of Western blotting were attached below them. (DOC $1266 \mathrm{~kb}$ )

\section{Abbreviations}

$A D T$, androgen deprivation therapy; $A R$, androgen receptor; $A R E$, androgen response element; CRPC, castration-resistant prostate cancer; DHT, dihydrotestosterone; FBS, fetal bovine serum; KLK, human kallikrein; NCOA, nuclear receptor coactivator; NCOR, nuclear receptor corepressor; PSA, prostatespecific antigen; siRNA, small interfering RNA

\section{Acknowledgements}

The authors thank Dr. T. Hoshii for assistance in preliminary studies and analyses.

\section{Funding}

It was supported in part by a Grant-in-Aid-for Scientific Research from the Ministry of Education, Culture, Sports, Science and Technology, Japan (\#21791493 and \#24592380).

\section{Availability of data and materials}

The datasets supporting the conclusions of this article are included within the article and its additional files (Additional files 1, 2, 3, 4, 5, 6,7 and 8).

\section{Authors' contributions}

Conception and initiation of the study was performed by TN and KT. KT, MT, and TN performed the experimental assays, and $\mathrm{KT}$ and $\mathrm{NH}$ conducted data analyses. TN, Fl and $\mathrm{NH}$ participated in the design of the study, and $\mathrm{KT}$ and $\mathrm{Fl}$ performed the statistical analysis. $\mathrm{KT}$ and $\mathrm{NH}$ wrote the manuscript, and $\mathrm{YT}$ helped to draft it. $\mathrm{NH}$ supervised all through the study. All authors read and approved the final version of the manuscript.

\section{Competing interests}

This work has not been funded by any commercial company. The authors declare that they have no competing interests.

\section{Consent for publication}

Not applicable.
Ethics approval and consent to participate

Not applicable.

\section{Author details}

${ }^{1}$ Division of Urology, Department of Regenerative and Transplant Medicine, Graduate School of Medical and Dental Sciences, Niigata University, Niigata, Japan. ${ }^{2}$ Division of Molecular Oncology, Department of Signal Transduction Research, Graduate School of Medical and Dental Sciences, Niigata University, Niigata, Japan. ${ }^{3}$ Asahimachi 1, Niigata 951-8510, Japan.

Received: 7 August 2015 Accepted: 23 May 2016

Published online: 25 May 2016

\section{References}

1. Ryan CJ, Tindall DJ. Androgen receptor rediscovered: the new biology and targeting the androgen receptor therapeutically. J Clin Oncol. 2011;29:3651-8.

2. George D, Moul JW. Emerging treatment options for patients with castration-resistant prostate cancer. Prostate. 2012;72:338-49.

3. Massard C, Fizazi K. Targeting continued androgen receptor signaling in prostate cancer. Clin Cancer Res. 2011;17:3876-83.

4. van Poppel H, Klotz L. Gonadotropin-releasing hormone: an update review of the antagonists versus agonists. Int J Urol. 2012;19:594-601.

5. Michaelson MD, Cotter SE, Gargollo PC, Zietman AL, Dahl DM, Smith MR. Management of complications of prostate cancer treatment. CA Cancer J Clin. 2008:58:196-213.

6. Gilbert SM, Kuo YF, Shahinian VB. Prevalent and incident use of androgen deprivation therapy among men with prostate cancer in the United States. Urol Oncol. 2011;29:647-53.

7. Mostaghel EA, Montgomery B, Nelson PS. Castration-resistant prostate cancer: targeting androgen metabolic pathways in recurrent disease. Urol Oncol. 2009;27:251-7.

8. Osanto S, van Poppel H. Emerging novel therapies for advanced prostate cancer. Ther Adv Urol. 2012;4:3-12.

9. Stein MN, Goodin S, Dipaola RS. Abiraterone in prostate cancer: a new angle to an old problem. Clin Cancer Res. 2012;18:1848-54

10. Zhang C, Wang L, Wu D, Chen H, Chen Z, Thomas-Ahner JM, et al. Definition of a FoxA1 Cistrome that is crucial for G1 to S-phase cell-cycle transit in castration-resistant prostate cancer. Cancer Res. 2011;71:6738-48.

11. Zhong WD, Qin GQ, Dai QS, Han ZD, Chen SM, Ling XH, et al. SOXs in human prostate cancer: implication as progression and prognosis factors. BMC Cancer. 2012;12:248.

12. Fujimoto $\mathrm{N}$, Miyamoto $\mathrm{H}$, Mizokami A, Harada S, Nomura M, Ueta $\mathrm{Y}$, et al. Prostate cancer cells increase androgen sensitivity by increase in nuclear androgen receptor and androgen receptor coactivators; a possible mechanism of hormone-resistance of prostate cancer cells. Cancer Invest. 2007;25:32-7

13. Okihara K, Ukimura O, Kanemitsu N, Mizutani $Y$, Kawauchi A, Miki T, et al Clinical efficacy of alternative antiandrogen therapy in Japanese men with relapsed prostate cancer after first-line hormonal therapy. Int J Urol. 2007;14:128-32

14. Suzuki H, Okihara K, Miyake H, Fujisawa M, Miyoshi S, Matsumoto T, et al. Alternative nonsteroidal antiandrogen therapy for advanced prostate cancer that relapsed after initial maximum androgen blockade. J Urol. 2008;180:921-7.

15. Okegawa T, Nutahara K, Higashihara E. Alternative antiandrogen therapy in patients with castration-resistant prostate cancer: a single-center experience. Int J Urol. 2010;17:950-5.

16. Chen CD, Welsbie DS, Tran C, Baek SH, Chen R, Vessella R, et al. Molecular determinants of resistance to antiandrogen therapy. Nat Med. 2004;10:33-9.

17. Kenneth $J L$, Thomas DS. Analysis of relative gene expression data using realtime quantitative PCR and the 2- $\Delta \Delta C T$ method. Methods. 2001;25:402-8.

18. Rodriguez C, Hughes-Davies L, Vallès H, Orsetti B, Cuny M, Ursule L, et al. Amplification of the BRCA2 pathway gene EMSY in sporadic breast cancer is related to negative outcome. Clin Cancer Res. 2004;17:5785-91.

19. Lubik AA, Gunter JH, Hendy SC, Locke JA, Adomat HH, Thompson V, et al. Insulin increases de novo steroidogenesis in prostate cancer cells. Cancer Res. 2011;71:5754-64.

20. Veldscholte J, Ris-Stalpers C, Kuiper GG, Jenster G, Berrevoets C, Claassen E, et al. A mutation in the ligand binding domain of the androgen receptor of 
human LNCaP cells affects steroid binding characteristics and response to anti-androgens. Biochem Biophys Res Commun. 1990;173:534-40.

21. Korenchuk S, Lehr JE, Mclean L, Lee YG, Whitney S, Vessella R, et al. VCaP, a cell-based model system of human prostate cancer. In Vivo. 2001;15:163-8.

22. Wang LG, Liu XM, Kreis W, Budman DR. Phosphorylation/dephosphorylation of androgen receptor as a determinant of androgen agonistic or antagonistic activity. Biochem Biophys Res Commun. 1999;259:21-8.

23. Wilding $\mathrm{G}$, Chen M, Gelmann EP. Aberrant response in vitro of hormoneresponsive prostate cancer cells to antiandrogens. Prostate. 1989;14:103-15.

24. Prescott J, Coetzee GA. Molecular chaperones throughout the life cycle of the androgen receptor. Cancer Lett. 2006;231:12-9.

25. Mangelsdorf DJ, Thummel C, Beato M, Herrlich P, Schutz G, Umesono K, et al. The nuclear receptor superfamily: the second decade. Cell. 1995;83:835-9.

26. Kaku N, Matsuda K, Tsujimura A, Kawata M. Characterization of nuclear import of the domain-specific androgen receptor in association with the importin alpha/beta and Ran-guanosine 5'-triphosphate systems. Endocrinology. 2008;149:3960-9.

27. Cutress ML, Whitaker HC, Mills IG, Stewart M, Neal DE. Structural basis for the nuclear import of the human androgen receptor. J Cell Sci. 2008;121:957-68

28. Gottlieb B, Pinsky L, Beitel LK, Trifiro M. Androgen insensitivity. Am J Med Genet. 1999;89:210-7.

29. Shiota M, Song Y, Yokomizo A, Tada Y, Kuroiwa K, Eto M, et al. Human heterochromatin protein 1 isoform HP1 beta enhances androgen receptor activity and is implicated in prostate cancer growth. Endocr Relat Cancer. 2010;17:455-67.

30. Shiota M, Yokomizo A, Tada Y, Inokuchi J, Tatsugami K, Kuroiwa K, et al. Peroxisome proliferator-activated receptor gamma coactivator-1alpha interacts with the androgen receptor (AR) and promotes prostate cancer cell growth by activating the AR. Mol Endocrinol. 2010;24:114-27.

31. Xu J, Wu RC, O'Malley BW. Normal and cancer-related functions of the p160 steroid receptor co-activator (SRC) family. Nat Rev Cancer. 2009;9:615-30

32. Otsuka T, Iguchi K, Fukami K, Ishii K, Usui S, Sugimura Y, et al. Androgen receptor W741C and T877A mutations in AIDL cells, an androgenindependent subline of prostate cancer LNCaP cells. Tumor Biol. 2011;32:1097-102.

33. Zhou HJ, Yan J, Luo W, Ayala G, Lin SH, Erdem H, et al. SRC-3 is required for prostate cancer cell proliferation and survival. Cancer Res. 2005;65:7976-83.

34. Yan J, Erdem H, Li R, Cai Y, Ayala G, Ittmann M, et al. Steroid receptor coactivator-3/AIB1 promotes cell migration and invasiveness through focal adhesion turnover and matrix metalloproteinase expression. Cancer Res. 2008;68:5460-8.

35. Taylor BS, Schultz N, Hieronymus H, Gopalan A, Xiao Y, Carver BS, et al. Integrative genomic profiling of human prostate cancer. Cancer Cell. 2010;18:11-22

36. Rosales T, Georget V, Malide D, Smirnov A, Xu J, Combs C, et al. Quantitative detection of the ligand-dependent interaction between the androgen receptor and the co-activator, Tif2, in live cells using two color, two photon fluorescence cross-correlation spectroscopy. Eur Biophys J. 2007:36:153-61.

37. Shi $X B$, Xue L, Shi D, de Vere WRW. Influence of short polyglutamine tracts and p160 coactivators on the transactivation of the androgen receptor. Cancer Biother Radiopharm. 2011;26:191-201.

38. Kino T, Ichijo T, Chrousos GP. FLASH interacts with p160 coactivator subtypes and differentially suppresses transcriptional activity of steroid hormone receptors. J Steroid Biochem Mol Biol. 2004;92:357-63.

\section{Submit your next manuscript to BioMed Central and we will help you at every step:}

- We accept pre-submission inquiries

- Our selector tool helps you to find the most relevant journal

- We provide round the clock customer support

- Convenient online submission

- Thorough peer review

- Inclusion in PubMed and all major indexing services

- Maximum visibility for your research

Submit your manuscript at www.biomedcentral.com/submit

) Biomed Central 